\title{
Fibroma of tendon sheath of the hand: Clinical and pathological study
}

\author{
Achilleas Thoma MD FRCSC FACS ${ }^{1}$, Jaggi Rao BSc MD², Samih Salama MD FRCPC ${ }^{3}$ \\ ${ }^{1}$ Department of Surgery, Division of Plastic and Reconstructive Surgery, St Joseph's Hospital and \\ McMaster University, Hamilton, Ontario; ${ }^{2}$ Department of Dermatology, University of Alberta, Calgary, \\ Alberta; ${ }^{3}$ Department of Pathology, St Joseph's Hospital and McMaster University, Hamilton, Ontario
}

\begin{abstract}
A Thoma, J Rao, S Salama. Fibroma of tendon sheath of the hand: Clinical and pathological study. Can J Plast Surg 2000;8(6):239-244.

Presented are seven cases of the rare tumour known as fibroma of tendon sheath of the hand. Diagnosis was uncertain before surgery. When the lesions were removed, they resembled schwannomas. Immunohistochemistry helped distinguish these tumours from giant cell tumours of the flexor sheath and schwannomas. The authors recommend that fibroma of the tendon sheath be included in the differential diagnosis of soft tissue neoplasms of the hand.
\end{abstract}

Key Words: Fibroma; Hand; Tendon sheath

\begin{abstract}
Fibrome de la gaine du tendon de la main : Étude clinique et pathologique
RÉSUMÉ : Nous présentons ici sept cas d'une tumeur rare connue sous le nom de fibrome de la gaine du tendon de la main. Le diagnostic était non confirmé avant la chirurgie. Lorsque les lésions ont été excisées, elles ressemblaient à des schwannomes. Les testes d'immunohistochimie ont contribué à faire la distinction entre ces tumeurs et des tumeurs à cellules géantes de la gaine du tendon fléchisseur et des schwannomes. Les auteurs recommandent d'inclure le fibrome de la gaine du tendon parmi les diagnostics différentiels des néoplasies des tissus mous de la main.
\end{abstract}

$\mathrm{F}$ ibroma of tendon sheath (FTS) is an unusual soft tissue tumour that tends to occur in the hands. In 1949, Geschickter and Copeland (1) first documented FTS as a distinct entity. In 1979, Chung and Enzinger (2) of the United States Armed Forces Institute of Pathology reported the clinical and pathological findings of 138 cases of FTS. Fewer than 30 cases have since been reported. Because FTS recurs in 25\% of patients, we believe that it has not been adequately recognized. The sample size of Chung and Enzinger's series (2) may give the false impression that FTSs are common. However, these 138 cases were collected from 70 institutions in North America over a 42-year period. We present seven new cases of FTS of the hand. In one case, FTS caused carpal tunnel syndrome.

\section{CASE PRESENTATIONS}

Cases were collected from the computerized index of the pathology department of St Joseph's Hospital, Hamilton, Ontario since 1983. Pathological and clinical reports were reviewed. The patients (four males and three females) ranged in age from 23 to 49 years (Table 1). The original histological diagnoses were made using light microscopy by a pathologist subspecializing in skin and soft tissue tumours. Sections were obtained from paraffin-embedded tissue. Five micron sections were stained using hematoxylin and eosin, and $3 \mu \mathrm{m}$ sections were used for immunohistochemical staining by a standard streptavidin-biotin-peroxidase method using monoclonal antibodies to vimentin (Dako Diagnostics Canada Inc), actin (Dako Diagnostics Canada Inc), S100 (Dako Diagnostics Canada Inc) and Factor VIII (or von Willebrand Factor) (Dako Diagnostics Canada Inc).

\section{CASE 1}

A 23-year-old female presented with a soft tissue tumour on the volar aspect of the proximal phalanx of the right index finger. She initially noticed the mass after the birth of her first child a year earlier.

At surgery, a firm, encapsulated, soft tissue tumour was found, which arose from the flexor sheath over the proximal phalanx (Figure 1). The tumour was white and rubbery, re-

This paper was presented in part at the International Federation of Societies for Surgery of the Hand Meeting, Vancouver, British Columbia, May 24 to 28,1998 Correspondence and reprints: Dr A Thoma, 200 James Street South, Suite 208, Hamilton, Ontario L8P 3A9. Telephone 905-523-0019, fax 905-523-0229, e-mailathoma@fhs.mcmaster.ca 
TABLE 1

Seven new cases of fibroma of tendon sheath of the hand

\begin{tabular}{|c|c|c|c|c|c|c|}
\hline $\begin{array}{l}\text { Case } \\
\text { number }\end{array}$ & $\begin{array}{l}\text { Age } \\
\text { (years) }\end{array}$ & Sex & Location & Associated tendons & Size $(\mathbf{c m})$ & Clinical features \\
\hline 1 & 23 & $\mathrm{~F}$ & Right index finger & Flexor sheath proximal phalanx & $1.5 \times 1.3 \times 1.1$ & Some discomfort with pressure application \\
\hline 2 & 49 & $\mathrm{~F}$ & Distal thumb & Flexor pollicis longus & $1.8 \times 2.0 \times 1.2$ & Unsightly lesion \\
\hline 3 & 40 & M & Middle palm & Flexor tendons zone III & $1.6 \times 1.6 \times 1.6$ & Sensory loss, pain, swelling \\
\hline 4 & 49 & M & Base of thumb & Flexor pollicis longus & $1.5 \times 1.5 \times 1.5$ & Pain with gripping, flexion and opposition \\
\hline 5 & 49 & M & Middle palm & Flexor tendons zone III & $2.5 \times 1.5 \times 1.0$ & Pain, difficulty flexing fingers, tingling \\
\hline 6 & 49 & $\mathrm{~F}$ & Left little finger & Profundus tendon & $0.7 \times 0.7 \times 0.7$ & Painful lump on flexor pollicis longus \\
\hline $7^{*}$ & 28 & M & Carpal tunnel & Ring and long flexor tendons & $3.5 \times 1.5 \times 1.0$ & Carpal tunnel syndrome \\
\hline
\end{tabular}

*Reference 3. F Female; M Male
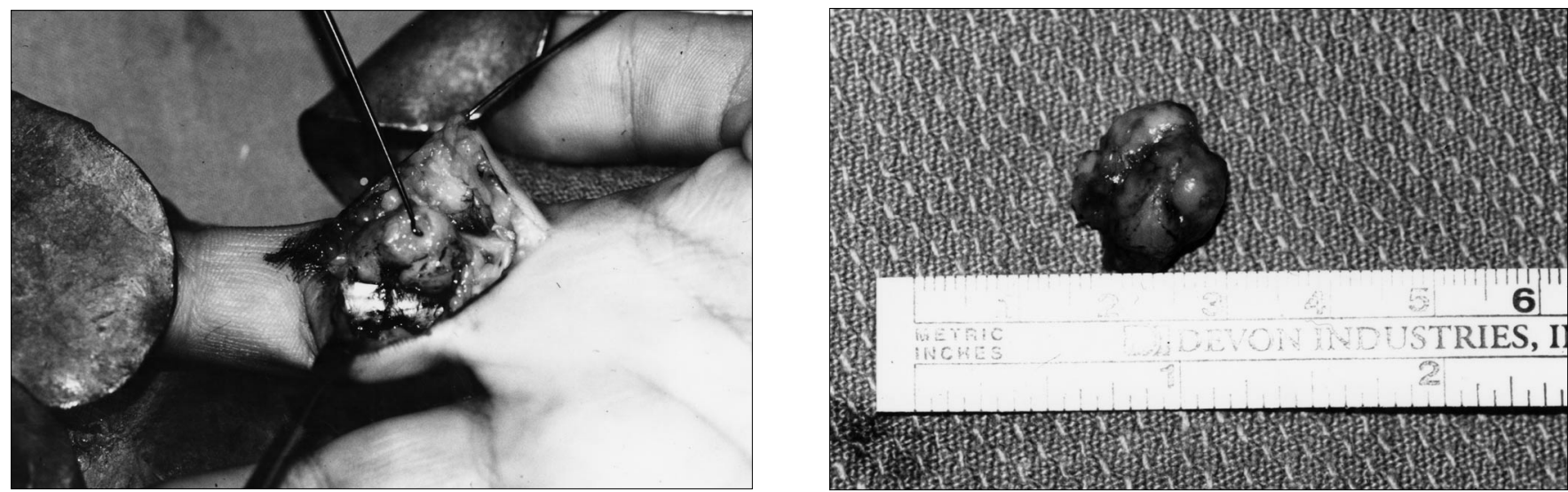

Figure 1) Left Fibroma of tendon sheath arising from flexor sheath of proximal phalanx of right index finger. Right Encapsulated nodular tumor after removal

sembling a schwannoma, but was not associated with any digital nerve. The tumour was removed with a portion of the flexor sheath.

Examination revealed a well circumscribed piece of firm white tissue measuring $1.5 \mathrm{~cm} \times 1.3 \mathrm{~cm} \times 1.1 \mathrm{~cm}$. Cut sections were yellow centrally and white at the periphery. Histologically, the tumour had a moderately cellular, fibrous background consisting of spindle cells with scattered, small blood vessels. A few histiocytes were seen in the background. Immunohistochemical staining revealed the spindle cells when stained with vimentin, but not when stained with S100 or actin antibodies. The blood vessels stained with the Factor VIII antibody.

One month after surgery, the patient continued to experience slight paraesthesia on the radial side of the index finger, although moving two-point discrimination was measured at $3 \mathrm{~mm}$.

\section{CASE 2}

A 49-year-old, white female presented with a large, soft tissue mass $(1.8 \mathrm{~cm} \times 2.0 \mathrm{~cm} \times 1.2 \mathrm{~cm})$ on the distal phalanx of the right thumb. This mass had developed in 10 months, and she had no symptoms. The interphalangeal joint moved normally and two-point discrimination of the thumb was normal.

The tumour was excised, and was found to be lobulated and well encapsulated. It was closely associated with the sheath of the flexor pollicis longus tendon. Part of the sheath was excised en bloc with the tumour.

High power microscopy showed fibrous stroma containing thin-walled, small blood vessels (Figure 2, Top) and spindle-shaped fibroblasts, consistent with FTS. Immunohistochemically, the lesion was well circumscribed (Figure 2, Bottom left). Factor VIII and vimentin antibodies revealed richly vascularized and moderately fibrocellular stroma (Figure 2, Bottom right). Three months after surgery, the patient had no symptoms or lesion recurrence.

\section{CASE 3}

A 40-year-old white male electrician presented with a painful mass in the middle of the left palm. He had numbness on both sides of the long finger. The mass had developed six weeks earlier. He had no history of injury and had discomfort with prolonged manual activity.

Examination revealed a tender, palpable lump in the middle of his palm. He had no infection or axillary adenopathy. Active flexion and extension of the fingers was normal. The moving two-point discrimination of the left long finger on both the ulnar and radial side was $9 \mathrm{~mm}$, indicating sensory abnormality.

The tumour was surgically removed; it measured $1.6 \mathrm{~cm}$ 

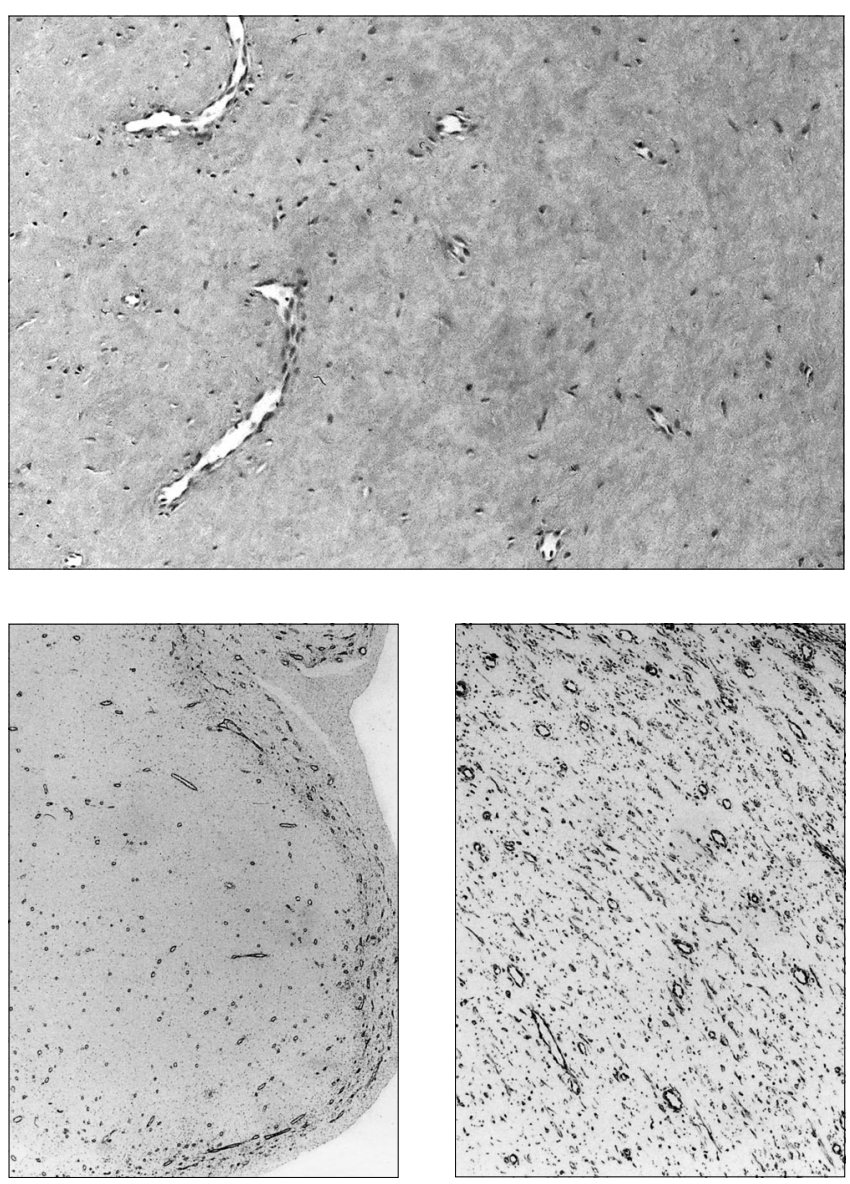

Figure 2) Top Close-up view showing fibrocollagenous stroma and many thin-walled blood vessels in the background (hematoxylin and eosin stain, original magnification $\times 50$ ). Bottom left Low power view showing well circumscribed lesion (original magnification $\times 25$ ). Bottom right Vimentin antibody outlining walls of small blood vessels and stromal cells (immunoperoxidase staining, originial magnification $\times 50$ )

in diameter and appeared nodular. The tumour was located between the flexor tendons and the lumbrical of the long finger, and appeared to arise from the tenosynovium of the flexor tendons. It was pale gray with a rubbery consistency, resembling a schwannoma. The tumour was completely excised along with some of the tenosynovium (Figure 3). It was encapsulated with a thin layer of adipose tissue and tenosynovium, and did not involve the digital nerves.

Microscopically, the tumour showed a benign encapsulated spindle cell neoplasm with moderately fibrous stroma, containing spindle cells and a richly vascular background composed of thin-walled, small blood vessels. The features were consistent with FTS.

Immunohistochemically, the spindle cells were vimentinpositive, actin-positive (patchy) and S100-negative. The Factor VIII antibody outlined the rich vascular background.

After surgery, the patient had relief of his pain but continued to have numbness of the long finger one month later. He was able to return to work one week after surgery.

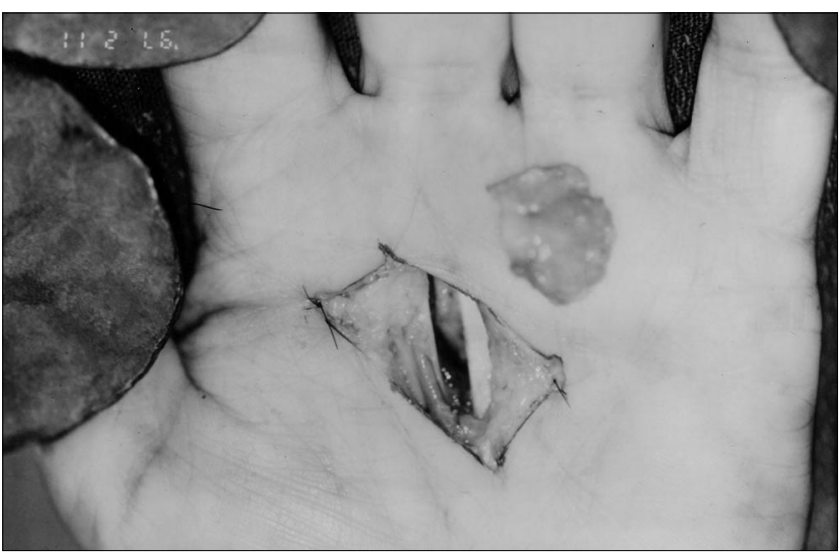

Figure 3) Excised tumour shown with defect remaining between the flexor tendons and lumbricals

\section{CASE 4}

A 49-year-old white male working as a casting and coremaker presented with a painful mass on the volar aspect of the right thumb. He had difficulty gripping because pressure on the tumour caused pain, but he had no loss of sensation. Triamcinolone had been injected into the lesion previously because of an erroneous diagnosis of ganglion, but there had been no relief of symptoms.

The tumour, measuring $1.5 \mathrm{~cm} \times 1.5 \mathrm{~cm} \times 1.5 \mathrm{~cm}$, was completely excised. It appeared to arise from the tenosynovium of the flexor pollicis longus tendon. The colour and consistency resembled a schwannoma, but the tumour was not attached to either digital nerve.

Histological sections showed a well circumscribed tumour with fibrous stroma that appeared vascular, with scattered, small blood vessels in the background. Slightly plump, histiocyte-like cells were also noted, but no giant cells were seen. The lesion was histologically consistent with FTS. Immunohistochemically, the spindle cells were strongly vimentinpositive and focally actin-positive but S100-negative. Factor VIII antibody stained the blood vessel walls.

One month after surgery, the patient had a good range of thumb movement and no symptoms.

\section{CASE 5}

A 49-year-old white male working as a voice dispatcher presented with a large, painful mass that had been growing for two years in the middle of the left palm. He had discomfort and was unable to flex his digits fully. He also complained of intermittent tingling that radiated to his forearm.

At surgery, a fibrous tumour $(2.5 \mathrm{~cm} \times 1.5 \mathrm{~cm} \times 1.0 \mathrm{~cm})$ was found to arise from the sheath of the flexor tendons of the left ring finger. Histology showed a well circumscribed and lobulated tumour. High power microscopy showed it to be a fibrous lesion consisting of spindle-shaped fibroblasts, with tremendous vasculature in the background made up of small, thin-walled blood vessels consistent with FTS. No giant cells were noted. Immunohistochemically, the stromal spindle cells reacted strongly positive with the vimentin antibody and nega- 
tive with the S100 antibody. Factor VIII staining showed strong positive marking of the vasculature framework.

Four months after surgery, the patient had no tumour recurrence and normal hand function.

\section{CASE 6}

A 49-year-old female presented with an expanding lesion on the pad of the left little finger distal phalanx, which was first noticed three years earlier. The lesion was painful when pressure was applied.

At surgery, the specimen was an oval, grey, well circumscribed nodule measuring $0.7 \mathrm{~cm} \times 0.7 \mathrm{~cm} \times 0.7 \mathrm{~cm}$. The cut surface was homogeneous and grey. Microscopic examination revealed a well circumscribed, densely hyalinized nodule containing small capillaries, consistent with FTS.

Immunohistochemically, the spindle cells stained positively with vimentin, but not with S100 or actin antibodies. The small blood vessels scattered in the background stained with Factor VIII antibody.

One month after surgery, the patient had full range of motion of her little finger and no symptoms.

\section{CASE 7}

This case was published previously (3). A 28-year-old white male presented with numbness of his left long and ring fingers. The mass at the distal edge of the carpal tunnel was tender to pressure. Provocative tests for carpal tunnel syndrome, including Tinel's and Phalen's tests, were positive. At surgery, a soft tissue mass was found in the carpal tunnel. It was well circumscribed, lobulated and measured $3.5 \mathrm{~cm} \times$ $1.5 \mathrm{~cm} \times 1.0 \mathrm{~cm}$.

Microscopically, the tumour was mildly cellular, consisting of spindle cells with collagenous and hyalinized stroma, and a rich vascular background of thin-walled blood vessels and slits; no giant cells were noted. The features were consistent with FTS. No neural structures were seen in the tumour. Immunohistochemically, the spindle cells were vimentinpositive and S100-negative. The blood vessel walls and slits stained with vimentin and Factor VIII antibodies.

After surgery, the patient's symptoms disappeared, and he was able to return to work four weeks later.

\section{DISCUSSION}

The etiology of FTS is unknown, but preceding trauma has been noted in $20 \%$ of cases, suggesting a possible risk factor $(3,4)$. In the series of cases presented in this paper, there was no history of reported trauma; however, microtrauma of the hand by routine manual labour may have been a predisposing factor. The incidence of FTS among benign soft tissue tumours is between $2 \%$ and $3.5 \%$. It is three times more common in men (5). The age range of patients has varied from five months to 77 years, with a mean of 36 years. These figures are based on a literature review of all known fibroma cases (1-21).

FTS occurs most commonly in the hand and wrist. In the Chung and Enzinger study (2), over $80 \%$ of the tumours were in the hand, with $49 \%$ in the digits, $20 \%$ in the midhand and
$12 \%$ at the wrist. In the digits, most tumours occur in the thumb, but they occur less often in the index and middle fingers. In the midhand, the tumours almost always occur in the palm. The present series shows a similar distribution of cases, from the fingertips to the wrist (Table 1). FTS has been reported in the feet (6), especially on the plantar aspect, and in the lateral aspect of the knee (7).

Clinically, the tumours present as solitary, slow growing, subcutaneous nodules. Localized tenderness or pain at the lesion site occurs in one-third of patients with FTS. Nerve compression from a growing tumour has caused paresthesia in some areas.

In the hand, FTS has a predilection for the flexor surfaces of the palm and wrist, and is associated with pain, decreased range of motion (8) and nerve impingement. Tumours on the volar aspect of the wrist have been known to be a rare cause of carpal tunnel syndrome $(3,9)$. Chung and Enzinger (2) reported two patients with FTS in the hand who showed symptoms of carpal tunnel syndrome. Subsequently, there were three other cases $(4,9,10)$, in addition to Case 7 (3) in the present series. Symptoms of carpal tunnel syndrome were quickly relieved by local excision along with carpal tunnel decompression.

In all cases, the tumours were attached or closely related to tendons or tendon sheaths. Nonetheless, they were readily removed at surgery. The literature indicates that most tumours are well circumscribed, multilobulated and often encapsulated, resembling giant cell tumors of the flexor sheath. The texture of the tumours is consistently reported as being firm or hard, with some elasticity $(4,11,12)$. The cut surface has a gray-white to yellowish-white colour, and sizes have ranged from 0.8 to $4.0 \mathrm{~cm}$, with an average of $2.0 \mathrm{~cm}$. In all cases of the present series, the cut surface of the tumours resembled schwannoma in colour and consistency. The discrete finding that differentiates FTS from schwannoma is the absence of a 'feeding' fascicle from a peripheral nerve. In all cases, however, the tumour was attached to the tenosynovium around flexor tendons, but did not invade the tendons.

Microscopically, the most common appearance of FTS is a clearly delineated and sometimes encapsulated tumour $(2,7)$. An intimate association with tendons or tendon sheaths is often noted at the microscopic level and on gross examination $(13,14)$. Most of the tumours are multinodular or lobulated, with individual lobules composed of scattered, spindle-shaped cells having plump to slender nuclei $(15,16)$. The cytoplasm of these cells is fuchsinophilic with Masson's trichrome stain $(2,5)$. The spindle-shaped cells are arranged in fascicles and are occasionally accompanied by a prominent myxoid matrix (17). In some reports, occasional foci of myxoid change have been observed to contain stellate-shaped myofibroblasts $(2,18)$.

The cells of FTS are embedded in fibrous and sometimes dense eosinophilic stroma $(2,19)$. Within the fibrocollagenous stroma are scattered, thin-walled, small vascular channels that spread randomly in various configurations (19). Sometimes, cartilaginous metaplasia was recognized by the presence of chondrocytes (20). Some reports also describe foci of hyalinized, thick collagen bundles. Inflammatory 
TABLE 2

Pathological and immunohistological findings that differentiate fibroma of tendon sheath from other soft tissue hand tumours

\begin{tabular}{|c|c|c|c|}
\hline & Fibroma of tendon sheath & Giant cell tumour & Schwannoma \\
\hline Gross pathology & $\begin{array}{l}\text { White, firm, rounded, associated with } \\
\text { tendon tenosynovium }\end{array}$ & $\begin{array}{l}\text { Yellow-orange, firm, associated } \\
\text { with flexor sheath and joints }\end{array}$ & $\begin{array}{l}\text { Tan, firm and rounded, associated with } \\
\text { peripheral nerves }\end{array}$ \\
\hline \multicolumn{4}{|l|}{ Histology } \\
\hline Cellularity & Multinodular, usually sparse & Multinodular, variably cellular & Nodular, cellular (type A); sparse (type B) \\
\hline Stroma & $\begin{array}{l}\text { Fibrovascular (small, thin, slit-like } \\
\text { vessels throughout) }\end{array}$ & Fibrous & $\begin{array}{l}\text { Palisading whorls (type A); edematous (type B); } \\
\text { few thick, moderately-sized vessels }\end{array}$ \\
\hline Giant cells & Generally absent & Present and abundant & Absent \\
\hline \multicolumn{4}{|c|}{ Immunohistochemistry } \\
\hline Vimentin & Positive & Positive & Positive \\
\hline S100 & Negative & Negative & Positive \\
\hline Actin & Sometimes positive & Negative & Negative \\
\hline Factor VIII & Positive (outlines many small blood vessels) & Negative & Positive (outlines few medium-sized vessels) \\
\hline
\end{tabular}

cells, osteoclasts, giant cells and siderophages are notably absent from all FTS cases $(17,19)$.

Ultrastructurally, the tumour cells show a cytoplasm containing prominent rough endoplasmic reticulum with dilated cisternae $(7,15,19)$. Also observed were large numbers of free ribosomes, but only occasional mitochondria $(15,19)$. An electron microscopic study showed the cells of FTS to be identical to myofibroblasts, containing characteristic microfilament bundles with focal, dense bodies (7).

The differential diagnoses of soft tissue tumours of the hand include ganglia, epithelial inclusion cysts, schwannomas and giant cell tumours. Certain histological features aid in differentiating FTS from other soft tissue hand tumours, which are tabulated in Table 2 . FTS characteristically shows fibroblasts proliferating within a fibrovascular background $(2,18)$.

Immunohistochemically, the fibroblasts or stromal spindle cells stain positively with vimentin, indicating a connective tissue origin; they also sometimes stain positively with actin antibody, indicating myofibroblastic differentiation. Factor VIII antibody staining outlines the endothelium of the tumour's vasculature (16). Unlike schwannomas, in which schwann cells stain with S100 protein antibody, FTS stains negative with S100 protein; therefore, FTS can be differentiated immunohistochemically from a schwannoma (7). It may also be differentiated from malignant sarcomas by a lack of marked cellularity, pleomorphism and abnormal mitotic figures (21).

The most difficult differentiation is between FTS and giant cell tumours of the tendon sheath. Both tend to form on tendon sheaths of the hands, and are multinodular or multilobular (2). However, at the microscopic level, FTS cells are predominantly similar to fibroblasts or myofibroblasts, contrasting to the cells of giant cell tumours, which are mainly composed of rounded, histiocyte-like cells (7) and have the characteristics of synovial cells $(4,10)$. The hallmark in differentiating the two lies in the fact that FTS lacks giant cells, which are multinucleated cells composed of fused macrophages (17). Also, compared with giant cell tumours, FTS seems to occur more often in younger age groups and has a greater preference for the male gender $(2,17)$.
Treatment of FTS seems to be best achieved by complete local excision. This also applies for recurring lesions. As mentioned previously, the recurrence rate of FTS is high. In the literature, $24 \%$ of patients had one recurrence after the initial surgery (2). These recurrences tend to occur between one month and two years postoperatively, and may be related to pseudopod formation and separate tumour foci in adjacent connective tissue (5). It has been postulated that remnants of these foci after initial surgery may serve as the basis for recurrence in some cases (5). None of the present series contained evidence of recurrence. This could be attributed to complete excision or, likely, to the short duration of follow-up.

There is no documentation of mortality because of FTS, and by all accounts, FTS is benign with no accounts of metastasis.

ACKNOWLEDGEMENTS: The authors thank Karen Veltri MSc for her technical assistance in preparing this manuscript and Dr Campbell-Moscrop for his critical review.

\section{REFERENCES}

1. Geschickter CF, Copeland MM. Tumours of Bone, 3rd edn. Philadelphia: JB Lippincott, 1949:693-5.

2. Chung EB, Enzinger FM. Fibroma of tendon sheath. Cancer 1979;44:1945-54

3. Rao J, Thoma A, Salama S. Fibroma of tendon sheath as a cause of carpal tunnel syndrome. Can J Plast Surg 1997;5:176-8.

4. Sarma D, Weilbaecher TG, Rodriguez FH. Fibroma of tendon sheath. J Surg Oncol 1986;32:230-2.

5. Cooper PH. Fibroma of tendon sheath. J Am Acad Dermatol 1984;11:625-8.

6. Lourie JA, Lwin KY, Woods CG. Case report 734. Fibroma of tendon sheath eroding 3rd metatarsal bone. Skeletal Radiol 1992;21:273-5.

7. Hashimoto H, Tsuneyoshi M, Daimaru Y, Ushijima M, Enjoji M. Fibroma of tendon sheath: a tumour of myofibroblasts. A clinicopathologic study of 18 cases. Acta Pathol Jpn 1985;35:1099-107.

8. Feinberg MS. Fibroma of a tendon causing limited finger motion: A case report. J Hand Surg [Am] 1979;4:386.

9. Evangelisti S, Reale VF. Fibroma of tendon sheath as a cause of carpal tunnel syndrome. J Hand Surg [Am] 1992;17:1026-7.

10. Bertolotto M, Rosenberg I, Parodi RC, et al. Case report: Fibroma of tendon sheath in the distal forearm with associated median 
nerve neuropathy: US, CT and MR appearances. Clin Radiol 1996;51:370-2.

11. Millon SJ, Bush DC, Garbes AD. Fibroma of tendon sheath in the hand. J Hand Surg [Am] 1994;19:788-93.

12. Greene TL, Strickland JW. Fibroma of tendon sheath. J Hand Surg [Am] 1984;9:758-60.

13. Grenga TE. Intratendinous fibroma of flexor tendon. J Hand Surg [Am] 1990;15:92-3.

14. Moskovich R, Posner MA. Intratendinous aponeurotic fibroma. J Hand Surg [Am] 1988;13:563.

15. Pulitzer DR, Martin PC, Reed RJ. Fibroma of tendon sheath: A clinicopathologic study of 32 cases. Am J Surg Pathol 1989;13:472-9.
16. Humphreys S, McKee PH, Fletcher CDM. Fibroma of tendon sheath: A clinicopathologic study. J Cutan Pathol 1986;13:331-8.

17. Satti MB. Tendon sheath tumours: a pathological study of the relationship between giant cell tumour and fibroma of tendon sheath. Histopathology 1992;20:213-20.

18. Jablokow VR, Kathuria S. Fibroma of tendon sheath. J Surg Oncol 1982;19:90-2.

19. Smith PS, Pieterse AS, McClure J. Fibroma of tendon sheath. J Clin Pathol 1982;35:842-8.

20. Southwick GJ, Karamoskos P. Fibroma of tendon sheath with bone involvement. J Hand Surg [Br] 1990;15:373-5.

21. Lamovec J, Bracko M, Voncina D. Pleomorphic fibroma of tendon sheath. Am J Surg Pathol 1991;15:1202-5. 